\title{
Pathophysiology of diabetes: An overview
}

\author{
Mujeeb Z. Banday, Aga S. Sameer ${ }^{1}$, Saniya Nissar
}

Department of Biochemistry, Government Medical College and Associated Shri Maharaja Hari Singh Hospital, Srinagar, Kashmir, India, ${ }^{1}$ Department of Basic Medical Sciences, College of Medicine, King Saud Bin Abdul Aziz University for Health Sciences, King Abdullah International Medical Research Centre, National Guard Health Affairs, Jeddah, Saudi Arabia

\begin{tabular}{|c|}
\hline Access this article online \\
\hline Website: www.avicennajmed.com \\
\hline DOI: 10.4103/ajm.ajm_53_20 \\
\hline Quick Response Code: \\
\hline
\end{tabular}

\begin{abstract}
Diabetes mellitus is a chronic heterogeneous metabolic disorder with complex pathogenesis. It is characterized by elevated blood glucose levels or hyperglycemia, which results from abnormalities in either insulin secretion or insulin action or both. Hyperglycemia manifests in various forms with a varied presentation and results in carbohydrate, fat, and protein metabolic dysfunctions. Long-term hyperglycemia often leads to various microvascular and macrovascular diabetic complications, which are mainly responsible for diabetes-associated morbidity and mortality. Hyperglycemia serves as the primary biomarker for the diagnosis of diabetes as well. In this review, we would be focusing on the classification of diabetes and its pathophysiology including that of its various types.
\end{abstract}

Key words: Diabetes mellitus, endocrinopathies, gestational diabetes, maturity-onset diabetes of the young, neonatal diabetes

\section{INTRODUCTION}

Diabetes mellitus (DM), also known simply as diabetes is a complex metabolic disorder characterized by hyperglycemia, a physiologically abnormal condition represented by continued elevated blood glucose levels. Hyperglycemia results from anomalies in either insulin secretion or insulin action or both and manifests in a chronic and heterogeneous manner as carbohydrate, fat, and protein metabolic dysfunctions. Diabetes follows a progressive pattern with complex pathogenesis and varied presentation. ${ }^{[1,2]}$

Hyperglycemia and its associated carbohydrate, fat, and protein metabolic dysfunctions affect multiple organs of the body and disrupt their normal functioning. These disruptions progress gradually and arise mostly due to the adverse effects of hyperglycemia and its associated metabolic anomalies on the normal structure and functioning of micro- and macrovasculature, which lie at the core of organ structure, and function throughout the body. The structural and functional disruptions in organ system

Address for correspondence: Dr. Aga Syed Sameer,

Department of Basic Medical Sciences, College of Medicine,

King Saud Bin Abdul Aziz University for Health Sciences,

National Guard Health Affairs, P.O. Box 9515, Mail Code 6556,

Jeddah 21423, Saudi Arabia.

E-mail: agas@ksau-hs.edu.sa; agasy@ngha.med.sa vasculature lead to micro- and macrovascular complications. Organ damage, dysfunction, and, ultimately, organ failure characterize these complications and affect body organs, which include, in particular, eyes, kidneys, heart, and nerves. Eye-related complications result in retinopathy with progression to blindness. Kidney-associated complications lead to nephropathy and potential renal failure. Heartrelated complications include hypertension and coronary heart disease. Nerve-associated complications lead to neuropathy, which can be autonomic and/or peripheral. Cardiovascular, gastrointestinal, and genitourinary (including sexual) dysfunctions are characteristic manifestations of autonomic neuropathy, whereas foot infections including ulcers requiring amputations and Charcot joint (osteoarthropathy) are often associated with long-term peripheral neuropathy. ${ }^{[3-5]}$ The cerebrovascular disease, peripheral arterial disease, and coronary heart

This is an open access journal, and articles are distributed under the terms of the Creative Commons Attribution-NonCommercial-ShareAlike 4.0 License, which allows others to remix, tweak, and build upon the work non-commercially, as long as appropriate credit is given and the new creations are licensed under the identical terms.

For reprints contact: reprints@medknow.com

Cite this article as: Banday MZ, Sameer AS, Nissar S. Pathophysiology of diabetes: An overview. Avicenna J Med 2020;10:174-88. 
disease, together termed as atherosclerotic cardiovascular disease, are of common occurrence in diabetes and constitute one of the major causes of diabetes-associated morbidity and mortality. ${ }^{[1,4,5]}$

Diabetes with its ever-increasing global prevalence has emerged as one of the most important and challenging health issues confronting the human population of the present world. The increase in the prevalence of diabetes in most regions across the globe has been parallel to the rapid economic development, leading to urbanization and adoption of modern lifestyle habits. ${ }^{[6]}$ In the year 2019, the number of adult people aged $20-79$ years with diabetes has been estimated to be about 463 million, which represents $9.3 \%$ of the total world adult population. By the year 2030, this number has been estimated to increase to 578 million, representing $10.2 \%$ of the total world adult population and further increase to 700 million by the year 2045, which represents $10.9 \%$ of the total world adult population. In the year 2019, the prevalence of diabetes among men and women has been estimated to be $9.6 \%$ and $9.0 \%$, respectively, of the total respective gender world population. ${ }^{[7]}$ Furthermore, in the year 2019, approximately 4.2 million adult people aged 20-99 years died due to diabetes, and its associated complications and health expenditure on diabetes estimated to at least 760 billion USD, which represents $10 \%$ of the total spending on adults. Diabetes during pregnancy has been estimated to have affected more than 20 million live births ( 1 in 6 live births) in the year 2019. ${ }^{[8]}$

\section{CLASSIFICATION AND PATHOPHYSIOLOGY}

$\mathrm{DM}$ is characterized by complex pathogenesis and varied presentation and any classification of this disorder, therefore, is arbitrary, but nevertheless useful, and is often influenced by the physiological conditions present at the time of assessment and diagnosis. The classification currently used is based on both the etiology and the pathogenesis of disease and is useful in the clinical assessment of disease and for deciding the required therapy. According to this classification, diabetes can be divided into four main types or categories: type 1 diabetes mellitus (T1DM), type 2 diabetes mellitus (T2DM), gestational diabetes mellitus (GDM), and diabetes caused or associated with certain specific conditions, pathologies, and/or disorders [Figure 1]..$^{[1,9]}$

\section{Type 1 diabetes mellitus}

T1DM, also known as type 1A DM or as per the previous nomenclature as insulin-dependent diabetes mellitus (IDDM) or juvenile-onset diabetes, constitutes about 5-10\% of all the cases of diabetes. It is an autoimmune disorder characterized by T-cell-mediated destruction of pancreatic $\beta$-cells, which results in insulin deficiency and ultimately hyperglycemia. ${ }^{[10,11]}$ The pathogenesis of this autoimmunity,

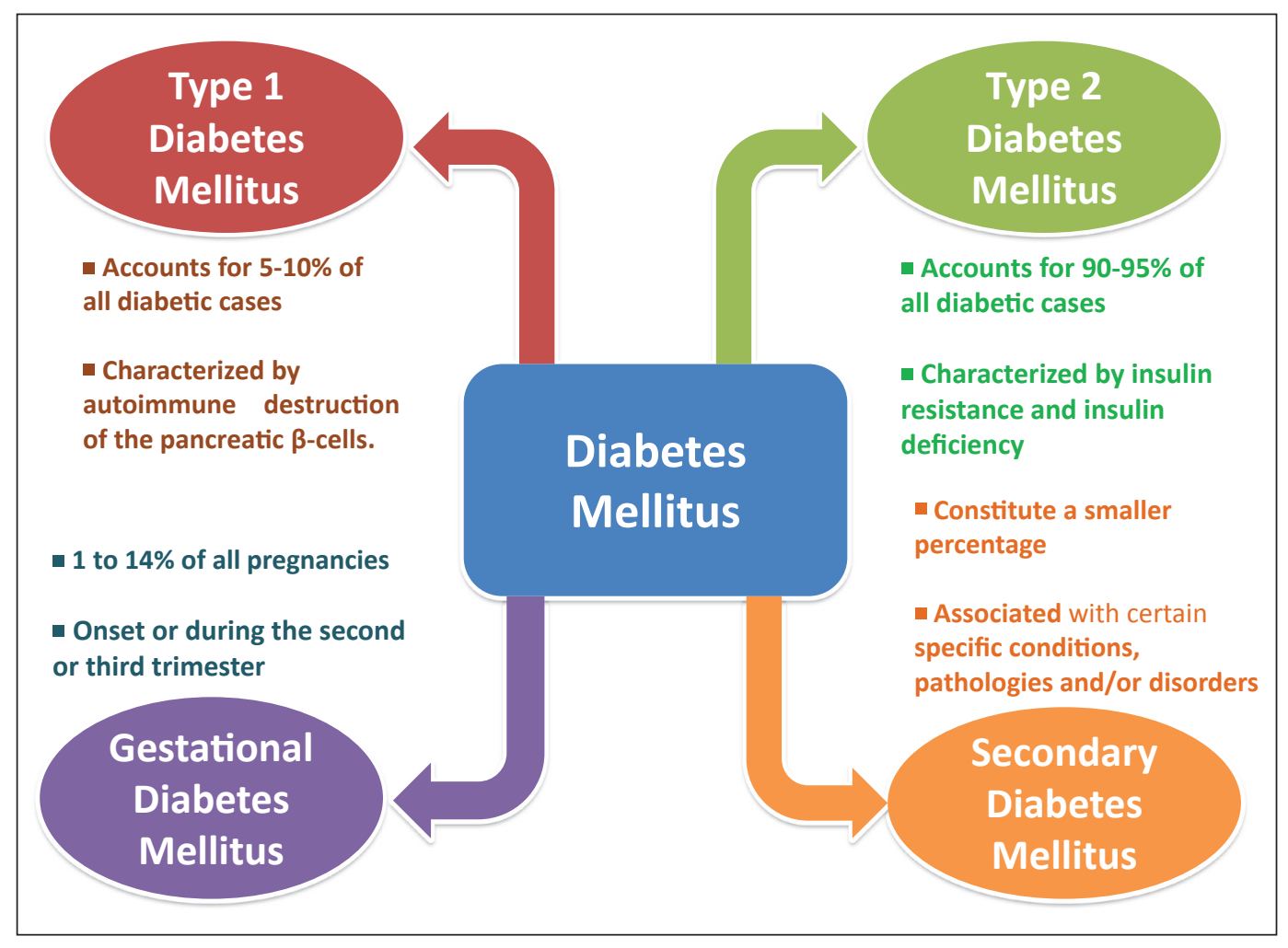

Figure 1: Four types of diabetes mellitus 
though not yet fully understood, has been found to be influenced by both genetic and environmental factors. The rate of development of this pancreatic $\beta$-cell-specific autoimmunity and the disorder itself is rapid in most of the cases as in infants and children (juvenile onset) or may be gradual as in adults (late onset).

The variability in the rate at which the immune-mediated destruction of the pancreatic $\beta$-cells occurs often defines the eventual progression of this disease. In some cases, children and adolescents, the $\beta$-cell destruction and subsequent failure occur suddenly, which can lead to diabetic ketoacidosis (DKA), often described as the first manifestation of the disease. In others, the disease progression is very slow with a mild increase in fasting blood glucose levels, which assumes a severe hyperglycemic form with or without ketoacidosis, only in the presence of physiological stress conditions such as severe infections or onset of other disorders. In some other cases, which include adults, $\beta$-cells may retain some degree of function to secrete only that quantity of insulin, which is only sufficient to prevent ketoacidosis for many years. However, due to progressive insulin deficiency, these individuals become insulin-dependent with the emergence of severe hyperglycemia and subsequent ketoacidosis. Despite the variable progression of this type of diabetes, the affected individuals in the beginning or in the middle or even in the later stages of their life become severely or absolutely insulin-deficient and become dependent on insulin treatment for their survival. This severe or absolute insulin deficiency irrespective of its occurrence at any age manifests itself as low or undetectable levels of plasma C-peptide. ${ }^{[1,10,11]}$

T1DM is an autoimmune disorder characterized by several immune markers, in particular autoantibodies. These autoantibodies are associated with the immunemediated $\beta$-cell destruction, characteristic of this disease. The autoantibodies include glutamic acid decarboxylase autoantibodies (GADAs) such as GAD65, islet cell autoantibodies (ICAs) to $\beta$-cell cytoplasmic proteins such as autoantibodies to islet cell antigen 512 (ICA512), autoantibodies to the tyrosine phosphatases, IA-2 and IA$2 \alpha$, insulin autoantibodies (IAAs), and autoantibodies to islet-specific zinc transporter isoform 8 (ZnT8). At least one of these autoantibodies can be used for the clinical diagnosis of this disease but usually more of these immune markers have been observed in approximately $85-90 \%$ of patients with new-onset T1DM. ${ }^{[1,12]}$ Of these autoantibodies, GAD65 is the most important and is present in about $80 \%$ of all T1DM individuals at the time of diagnosis, followed by ICAs present in $69-90 \%$ and IA- $2 \alpha$ found in $54-75 \%$ of all T1DM individuals at clinical presentation.
The IAAs are important immune markers present in infants and young children who are prone to diabetes and its prevalence decreases as the age of onset of diabetes increases. The presence of IAAs in these individuals who have not been previously treated with insulin is an important indication of developing T1DM. IAAs are present in about $70 \%$ of all infants and young children at the time of diagnosis. The IAAs also play an important inhibitory role toward insulin function in patients on insulin therapy. Although not often clinically significant but nevertheless, this immune response has been observed with varying degrees of severity in at least $40 \%$ of patients on insulin treatment and therefore shows differential clinical manifestations. ${ }^{[13]}$ These autoantibodies mostly consist of polyclonal immunoglobulin G (IgG) antibodies and differ in their affinities and binding capacities toward insulin. IAAs can either be high insulin affinity/ low insulin-binding capacity or low insulin affinity/high insulin-binding capacity. The low insulin affinity/high insulin-binding capacity IAAs are responsible for clinical manifestations. At high titers, the binding of these antibodies to insulin prevents or delays its action and is responsible for characteristic hyperglycemia in the immediate postprandial period, which leads to significantly increased insulin requirements followed by unpredictable hypoglycemic episodes (postprandial hypoglycemia) observed later. ${ }^{[14]}$

These autoantibodies assume more clinical and diagnostic importance in some cases, particularly adults, with lateonset of this disease where the destruction of the pancreatic $\beta$-cells occurs at a very slow rate and often the disease masquerades as in T2DM. In such cases, these autoantibodies enable the correct diagnosis of this disorder as the T1DM, rather than the most common T2DM. This type of diabetes is often described as "Latent Autoimmune Diabetes in Adults (LADA)," also known as "slowly progressing insulindependent diabetes." ${ }^{[15]}$

LADA is the most common form of adult-onset autoimmune diabetes and accounts for $2-12 \%$ of all diabetic cases in the adult population. ${ }^{[16]}$ Of the autoantibodies, GADAs are the most important and sensitive markers for LADA followed by ICAs. However, the IAAs, autoantibodies to the tyrosine phosphatases-IA-2 and IA-2 $\alpha$, and autoantibodies to islet-specific zinc transporter isoform 8 (ZnT8) which are observed in patients with juvenile- or young-onset T1DM are detectable in only a small number of cases in LADA. ${ }^{[17]}$ In a study on LADA (Action LADA study), GADAs were the only diabetes-specific autoantibodies detected in $68.6 \%$ of total screened subjects whereas IA- $2 \alpha$ and ZnT8A represented the single-type autoantibody detections in 5\% and $2.3 \%$ of all the screened study subjects. In the same study, more than one type of autoantibody was detected in 
$24.1 \%$ of study subjects. ${ }^{[18]}$ LADA is also sometimes referred to as T2DM with ICAs.

Besides the characteristic immune-mediated pancreatic $\beta$-cell destruction, several other autoimmune disorders including myasthenia gravis, Addison's disease (primary adrenal insufficiency), celiac sprue (celiac disease), pernicious anemia, vitiligo, Hashimoto's thyroiditis, Graves' disease, dermatomyositis, autoimmune gastritis, and autoimmune hepatitis have been observed with an increased incidence in patients with T1DM. ${ }^{[1,10,19,20]}$ The autoimmune nature of this disease and its association with other autoimmune conditions mainly stem from the strong association of this disorder with human leukocyte antigen (HLA), its linkage to the DQA and DQB genes, and its direct influence by DRB genes. All of these are hotspot gene regions associated with immune response including autoimmunity. The genomewide association studies have shown a strong association of this disease with HLA-DR3 and HLA-DR4 haplotypes and the exclusive association of DR4-DQB1I0302 haplotype with the autoimmune destruction of the $\beta$-cells. As with other diseases, these various HLA haplotypes can increase or decrease the susceptibility toward the T1DM. ${ }^{[21-23]}$ However, several non-HLA genes or gene regions also influence the susceptibility to this disease. The most prominent among them is the insulin gene (INS) region, designated as IDDM2 located on chromosome 11p5.5. The variable number of tandem repeats in the promoter region of this gene region has been observed to influence the susceptibility toward this disease. ${ }^{[24]}$ Besides IDDM2, CTLA-4, PTPN-22, and CD25 are other non-HLA genes associated with the disease. ${ }^{[25]}$ The patients with this type of diabetes can be but are rarely obese at the time of assessment and diagnosis. ${ }^{[1,10]}$

\section{Idiopathic diabetes}

Idiopathic diabetes, also referred to as ICA-negative or type $1 \mathrm{~B}$ diabetes, includes the forms of diabetes which are similar to T1DM in presentation but characterized by variable nonimmune $\beta$-cell dysfunction without any observed HLA association unlike T1DM and hence, sometimes it is also described as a separate type of DM. This type of diabetes exhibits a strong pattern of inheritance and has been observed in only a minority of patients, of Asian or African-Caribbean origin. The etiology of idiopathic diabetes remains largely unknown.

The disease is characterized by severe but varying degrees of insulin deficiency (insulinopenia) which can exhibit episodic patterns concomitant with varying degrees of severity and episodic DKA. These patients, therefore, may require insulin replacement therapy initially but the need for the therapy may not be absolute and may vary in accordance with the episodic patterns of insulinopenia and ketoacidosis characteristic of these forms of T1DM. ${ }^{[26]}$

\section{Type 2 diabetes mellitus}

T2DM, also known as non-insulin-dependent diabetes mellitus (NIDDM) or adult-onset diabetes, as per the previous nomenclature, constitutes about $90-95 \%$ of all the cases of diabetes. This type of diabetes is characterized by two main insulin-related anomalies: insulin resistance and $\beta$-cell dysfunction. ${ }^{[27-29]}$ Insulin resistance results from disruption of various cellular pathways, which lead to a decreased response, or sensitivity of cells in the peripheral tissues, in particular the muscle, liver, and adipose tissue toward insulin. In the early stages of the disease, decreased insulin sensitivity triggers $\beta$-cells hyperfunction to achieve a compensatory increase in insulin secretion to maintain normoglycemia. The higher levels of circulating insulin (hyperinsulinemia), thus, prevent hyperglycemia. However, gradually, the increased insulin secretion by $\beta$-cells is not able to compensate sufficiently for the decrease in insulin sensitivity. Moreover, $\beta$-cell function begins to decline and $\beta$-cell dysfunction eventually leads to insulin deficiency. As a result, normoglycemia can no longer be maintained and hyperglycemia develops. Although insulin levels are decreased, the secretion of insulin in most cases is sufficient to prevent the occurrence of DKA. ${ }^{[29]}$ But DKA may occur during severe stress conditions such as those associated with infections or other pathophysiological scenarios. DKA may also be precipitated by the use of certain drugs including sodium-glucose co-transporter-2 (SGLT2) inhibitors, corticosteroids, and atypical antipsychotics (second-generation antipsychotic drugs). ${ }^{[30,31]}$ In absence of any severe physiological stress conditions, patients with T2DM often do not require any insulin therapy both at the time of disease onset and even after, throughout their lifetime. ${ }^{[27-29]}$

T2DM progresses very slowly and asymptomatically with even mild hyperglycemia developing over years and as such remains largely undiagnosed until the appearance of classic symptoms associated with severe hyperglycemia such as weight loss, growth impairment, blurred vision, polyuria, and polydipsia in the advanced stages of the disease. The pathogenesis/etiology of this form of diabetes is complex and involves multiple known and unknown factors, which in a conclusive manner can be described as a combination of genetic (polygenic) predispositions and strong environmental influences. T2DM has been more frequently associated with increasing age, obesity, family history of diabetes, physical inactivity, and adoption of modern lifestyles: with prior GDM in women and with pathophysiological conditions such as hypertension and 
dyslipidemia. It occurs more frequently in individuals belonging to certain racial or ethnic groups including Native Americans (American Indians), Asian Americans, African Americans, Hispanic, and Latino. The frequent occurrence of T2DM in the mentioned racial or ethnic groups and its observed strong association with first-degree blood relations point strongly toward the role of genetic factors in the etiology of this disease, but these factors are complex and remain largely unspecified. However, unlike T1DM, no association of this disease has been found with genes involved in the immune response including autoimmunity and consequently there is no immune-mediated pancreatic $\beta$-cell destruction. ${ }^{[32,33]}$

Obesity plays an important role in the homeostatic regulation of systemic glucose due to its influence on the development of insulin resistance through its effect on the sensitivity of tissues to insulin and as such most but not all patients with T2DM are overweight or obese. ${ }^{[34]}$ The increased body fat content, a characteristic of obesity, is such an important risk factor for T2DM that not only the total amount but also the distribution of body fat itself defines the development of insulin resistance and subsequently hyperglycemia. The increased abdominal fat or visceral obesity has been frequently associated with this type of diabetes in comparison to increased gluteal/subcutaneous fat or peripheral obesity. ${ }^{[35]}$ Due to its strong association with increased body fat content or obesity, the patients with T2DM often present with various cardiovascular risk factors such as hypertension and lipoprotein metabolic abnormalities characterized by elevated triglycerides and low levels of high-density lipoproteins (HDLs). Due to its lifelong duration and associated diverse metabolic derangements characteristic of hyperglycemia, T2DM, particularly in the middle and later decades, is frequently associated with the development of various microvascular and macrovascular complications. Figure 2 enlists some of the main risk factors of T2DM.

\section{Gestational diabetes mellitus}

GDM is defined as any degree of glucose intolerance or diabetes diagnosed at the outset or during pregnancy, usually the second or third trimester. This definition earlier also included any undetected T2DM which may begin prior to or occur at the time of pregnancy onset. However, the latest recommendations of the International Association

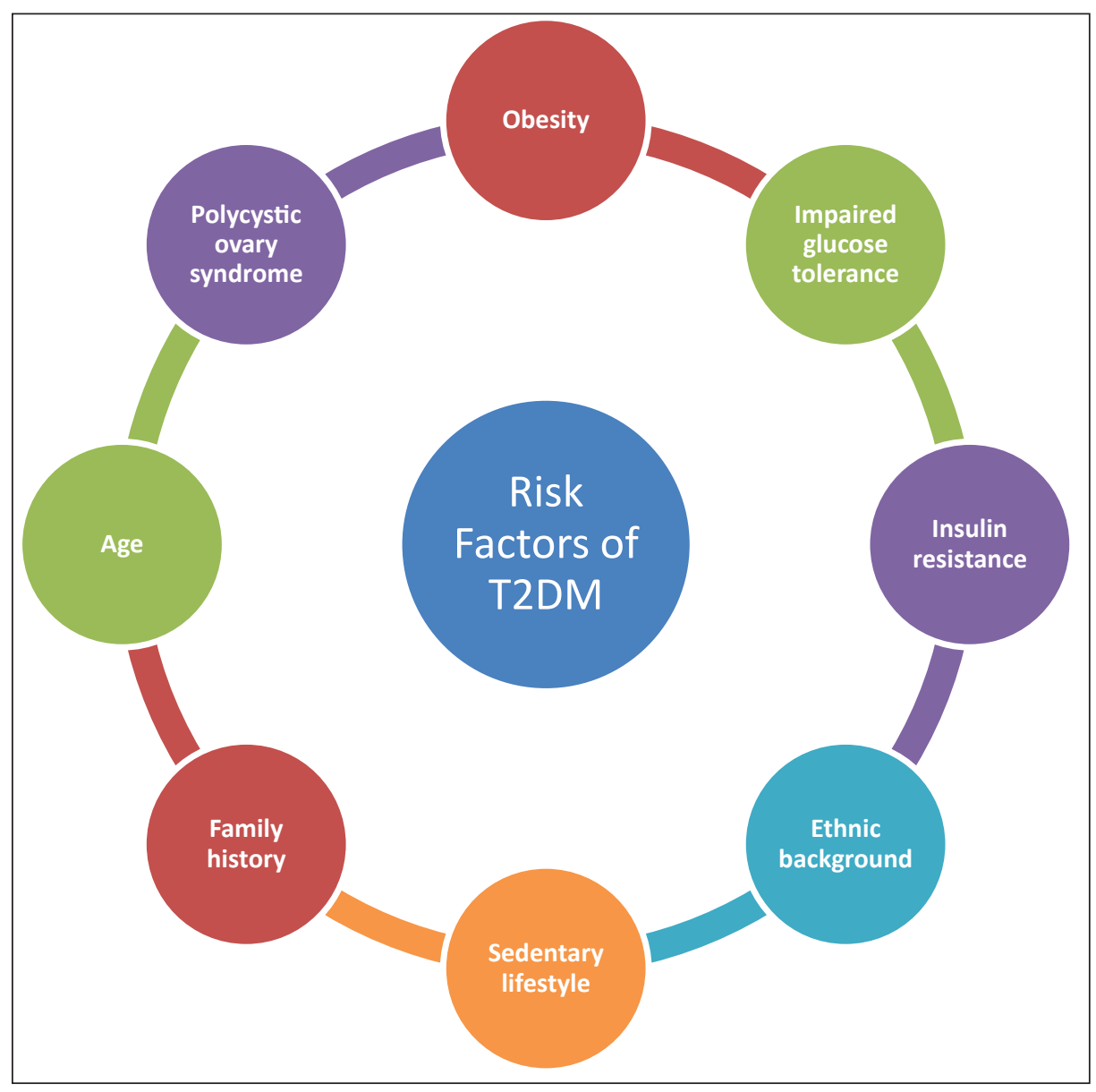

Figure 2: Some of the main risk factors of type 2 diabetes mellitus 
of the Diabetes and Pregnancy Study Groups exclude from this definition diabetes diagnosed at the pregnancy onset or afterward in high-risk women such as with obesity where any degree of glucose intolerance is described as previously undiagnosed overt diabetes rather than GDM. GDM is different from any preexisting diabetes in women undergoing pregnancies and usually resolves soon after childbirth or termination of pregnancy. ${ }^{[1,36]}$

During early pregnancy, both the fasting and post-prandial blood glucose levels are usually lower than normal but the blood glucose levels increase during the third trimester of pregnancy, and in cases where this blood glucose level reaches the diabetic levels, the condition is described as GDM. More than $90 \%$ of all the cases of diabetes and its complications that occur during pregnancy can be attributed to GDM. The incidence of GDM varies from $1 \%$ to $14 \%$ of all pregnancies and its prevalence is greatly influenced by the populations under study. GDM occurs more frequently in certain racial or ethnic groups than others and this influence of ethnicity on risk of GDM is very important and has long been established. The prevalence of GDM is highest among Asian Indians, higher in aboriginal Australians, Middle Eastern (Lebanese, Syrian, Iranian, Iraqi, or Afghanistan), Filipina, Pacific Islanders, and Chinese, Japanese, Korean, and Mexican women. The prevalence is lower in blacks and lowest among non-Hispanic white women. ${ }^{[37,38]}$ The risk of GDM increases with age, obesity, previous pregnancy with large babies, and any previous history of impaired glucose tolerance or GDM. ${ }^{[39,40]}$ Furthermore, GDM has been associated with an increased lifetime risk of developing T2DM. The regular and lifetime screening for any kind of glucose impairment is, therefore, highly recommended in order to ensure early diagnosis of T2DM in such individuals. ${ }^{[41-43]}$

\section{Other types of diabetes}

Besides T1DM, T2DM, and GDM, diabetes in various other forms, though in smaller percentages with respect to overall diabetic incidence scenario, has been found to be associated with some specific conditions including various pathologies and/or several disorders. The prominent among these types of diabetes include diabetes resulting from the monogenic defects in $\beta$-cell function and those due to genetic abnormalities in insulin action, endocrinopathies, exocrine pancreatic pathologies, and several other specific conditions.

Diabetes caused due to the monogenic defects in B-cell function

Diabetes resulting from monogenic defects in $\beta$-cell function constitutes only $0.6-2 \%$ of all the cases of diabetes and mainly includes maturity-onset diabetes of the young (MODY) and neonatal diabetes, besides other but rare types.

Maturity-onset diabetes of the young

MODY is a genetically, metabolically, and clinically heterogeneous group of mostly non-insulin-dependent diabetes, resulting from mutations in several specific genes involved in pancreatic $\beta$-cell function, which affects glucose sensing and subsequent insulin secretion with no or minimal defects, if any, in insulin action. MODY, as the name suggests, has an early onset with glucose tolerance impairment and hyperglycemia occurring usually before the age of 25 years and is often misdiagnosed as T1DM or T2DM. ${ }^{[4,45]}$ MODY accounts for less than $2 \%$ of all the cases of diabetes ${ }^{[46]}$ and $1-6 \%$ of all the pediatric cases of diabetes. ${ }^{[47]}$ MODY follows an autosomal dominant inheritance pattern and typically involves the vertical transmission of the disorder through at least three generations and exhibits a phenotype shared by all family members with diabetes. ${ }^{[48]}$ To date, MODY has been associated with mutations in one of the 14 genes identified so far and these genes are mostly located on different chromosomes. ${ }^{[1,9,46,49]}$ Figure 3 provides a graphical representation of various MODY subtypes along with their alternative names based on genes involved. The most common forms of this group of diabetes are designated as MODY2 and MODY3 which together account for more than $80 \%$ of all the cases of this type of diabetes. ${ }^{[50,51]}$

MODY2 (GCK MODY). MODY2 results from one or several of more than 200 loss-of-function mutations in the glucokinase (GCK) gene located on chromosome 7p13 and accounts for $15-25 \%$ of all MODY cases. ${ }^{[50,52]}$ GCK gene codes for GCK enzyme, which catalyzes the first and rate-limiting step of glycolytic phosphorylation of glucose to glucose-6-phosphate at a rate proportional to the glucose concentration. This unique catalytic property allows the GCK enzyme to function as a sort of a glucose sensor and enables the $\beta$-cells to elicit an insulin secretion response appropriate to the existing concentrations of glucose. ${ }^{[53]}$ The loss-of-function mutations characteristic of MODY2 disrupt this glucose-sensing function of the GCK enzyme such that only hyperglycemic but not normoglycemic levels can elicit a normal insulin secretion response from the $\beta$-cells. In MODY2, the fasting hyperglycemia remains mild but persistent and stable and the disorder is noninsulin-dependent. MODY2 is clinically nonprogressive with mild or no symptoms and is usually not associated with the development of microvascular and macrovascular complications. GCK gene is a mutational hotspot region and more than 600 mutations have been identified in the 10 exons of this gene, which have been associated with both hyperglycemia and hypoglycemia. ${ }^{[54]}$ 


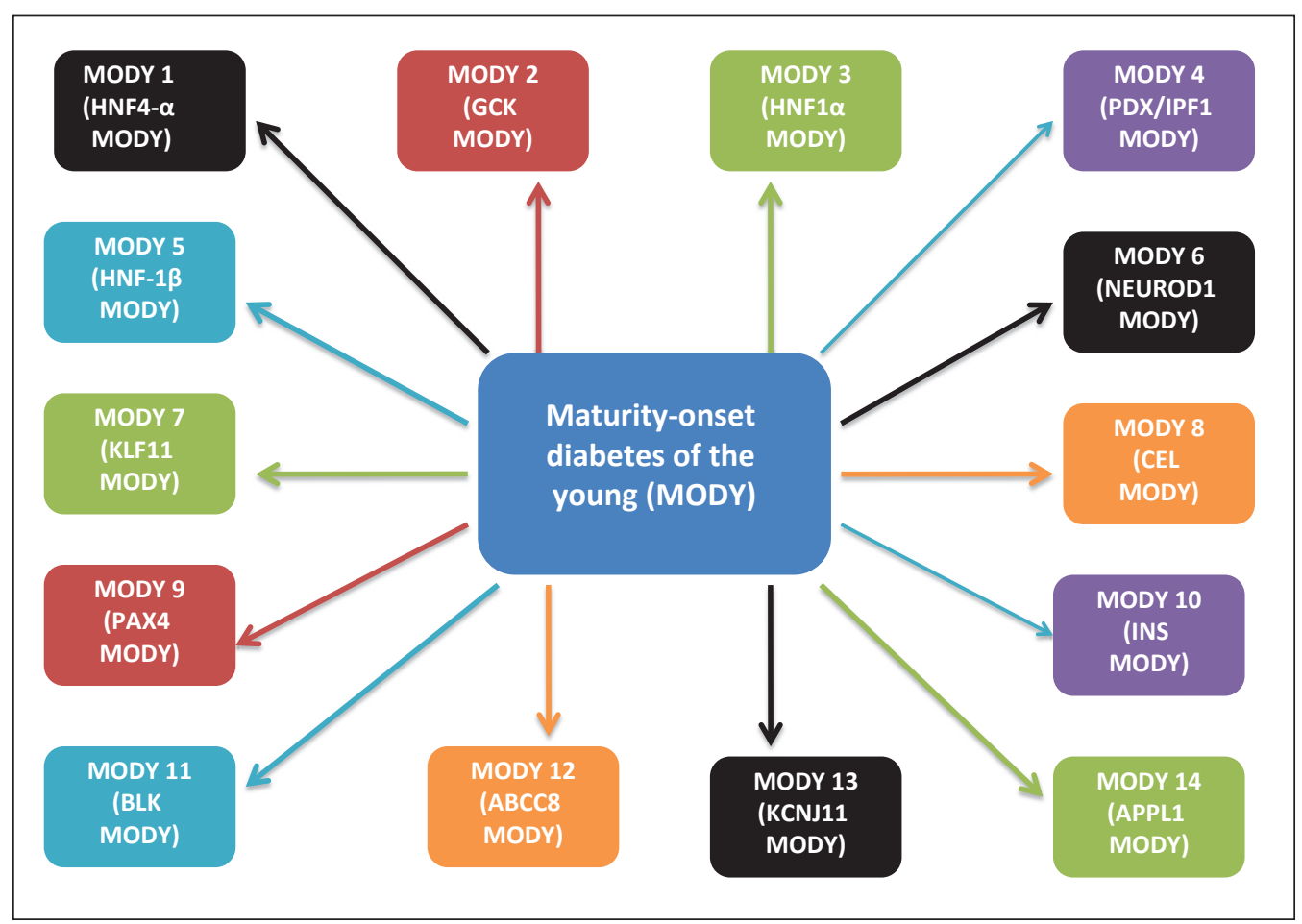

Figure 3: Types of maturity-onset diabetes of the young and their alternative names based on genes involved

MODY3 (HNF-1 $\alpha$ MODY) and MODY1 (HNF-4 $\alpha$ MODY). MODY3 results from the loss-of-function mutations in hepatocyte nuclear factor (HNF)-1a gene located on chromosome $12 \mathrm{q} 24$, which codes for the transcription factor, HNF-1 $\alpha$ (transcription factor MODY) and accounts for $30-50 \%$ of all MODY cases. ${ }^{[51]} \mathrm{HNF}-1 \alpha$ is expressed in the kidney, liver, intestine, and pancreatic $\beta$-cells and is involved in regulating the expression of several hepatic genes many of which are involved in glucose metabolism including glucose transporter 1 and 2 (GLUT1 and GLUT2). More than 400 mutations have been identified in HNF-1 $\alpha$ gene. ${ }^{[55]}$ MODY 3 presents with a symptomatic rapid progression to overt diabetes reflected through a progressive impairment from glucose intolerance to severe hyperglycemia, often leading to T1DM and T2DM like microvascular and macrovascular complications. MODY3 has been associated with a decreased pancreatic $\beta$-cell mass due to an increased rate of $\beta$-cell apoptosis, particularly from the third decade of life onward, and therefore, MODY3 is characterized by a progressive decrease in insulin secretion. ${ }^{[56]}$ Depending on the hyperglycemic severity and duration since onset, MODY3 may be or may not be insulin-dependent.

MODY1 accounts for around 5\% of all MODY cases. MODY1 is caused due to the loss-of-function mutations in the transcription factor, HNF-4a gene located on chromosome 20q13. HNF-4a is mainly expressed in the liver and also in kidney and pancreatic $\beta$-cells and regulates the expression of genes involved in glucose transport, metabolism, and nutrient-induced insulin secretion and also triglyceride metabolism and lipoprotein biosynthesis. ${ }^{[57]}$ HNF- $4 \alpha$ mutation is characterized by a progressive defect and a decline in insulin secretion from infancy onward and resembles clinically with MODY3. It is associated with hyperinsulinemic hypoglycemia in the neonatal period, which begins to remit during infancy, and as such, the decline in insulin production starts in infancy but the emergence of hyperglycemia and subsequent full-blown diabetes occurs during adolescence. ${ }^{[47,58]} \mathrm{HNF}-4 \alpha$ mutation and hence MODY1 have been associated with decreased levels of apolipoprotein-apoAII, apoCIII, and apoB and HDLs and increased levels of low-density lipoproteins (LDLs).

Hyperglycemia associated with HNF-1 $\alpha$ and HNF-4a mutations in MODY3 and MODY1, respectively, can be efficiently controlled through the treatment with low-dose sulfonylureas. These agents maintain efficacy or remain effective for many years and are preferred first-line of treatment in these patients compared to insulin and other therapies used in T1DM and T2DM. However, to ensure proper treatment, an early and accurate diagnosis is very important to avoid mislabeling these MODY types as T1DM or T2DM and prevent administration of inappropriate avoidable therapies in these patients. ${ }^{[59,60]}$

MODY5 (HNF-1 $\beta$ MODY). MODY5 results from mutations in the transcription factor, HNF- $1 \beta$ gene located on 
chromosome 17q12 and accounts for around 5\% of all cases of MODY. ${ }^{[61,62]}$ HNF-1 $\beta$ is involved in the regulation of genes that are associated with various embryonic developmental processes, in particular, the genesis of various organs including the liver, pancreas, lungs, gut, kidney, and genitourinary tract. ${ }^{[63]}$ MODY5 develops in early adolescence or adulthood. HNF-1 $\beta$ mutations that result in MODY 5 often present as renal cysts, renal cysts and diabetes syndrome, renal dysplasia, hypoplastic glomerulonephritic kidney disease, urinary tract malformation, ${ }^{[64,65]}$ and reduced birth weight. ${ }^{[66]}$ Some of these conditions are evident from the 17 th week of gestation ${ }^{[65]}$ or are seen in infants or young children, independent of the hyperglycemic status. ${ }^{[47]}$ Renal dysfunction, ${ }^{[65]}$ liver dysfunction, and pancreatic abnormalities ${ }^{[67]}$ are common as the disorder develops and end-stage renal disease develops in half of the patients with MODY 5 by 45 years of age independent of diabetic kidney disease status. ${ }^{[65]}$ Genitourinary tract malformations especially uterine abnormalities such as rudimentary uterus in addition to vaginal aplasia have also been reported in MODY5. ${ }^{[67]}$ Insulin dependence develops relatively earlier due to liver and pancreatic abnormalities, in particular, hepatic insulin resistance and pancreatic hypoplasia. ${ }^{[47,68]}$ Hyperuricemia, gout, low HDL levels, and elevated triglyceride levels are commonly observed in patients with MODY5. ${ }^{[61,69]}$

Other types of MODY. Relatively rare and less common types of MODY, which account for less than $1 \%$ of all MODY cases, include as follows:

MODY4 (PDX-1/IPF-1 MODY): MODY4 results from mutations in the transcription factor, pancreatic and duodenal homeobox-1(PDX-1), also known as insulin promoter factor (IPF)-1 gene located on chromosome 13q12.2. ${ }^{[70]}$ PDX-1/IPF-1 is involved in the development of exocrine and endocrine pancreas and plays an important role in regulating the expression of insulin, glucagon, GLUT2, and GCK encoding genes. ${ }^{[71,72]}$ Homozygous mutations in PDX-1/IPF-1 gene result in pancreas agenesis, hypoplasia, and pancreatic exocrine insufficiency and in permanent neonatal diabetes (PND) whereas heterozygous PDX-1/IPF-1 gene mutations cause $\beta$-cell impairment, which leads to defective insulin secretion and hyperglycemia. ${ }^{[73,74]}$

MODY6 (NEUROD1 MODY): MODY6 results from mutations in the transcription factor, neurogenic differentiation factor-1(NEUROD1) gene located on chromosome $2 \mathrm{q} 31 .{ }^{[75]}$ NEUROD1 belongs to the basic helix-loop-helix family of transcription factors and is involved in the regulation of several cell differentiation pathways associated with neuronal and pancreatic development, in particular, those involved in endocrine islet cells (islets of Langerhans) differentiation including the pancreatic $\beta$-cells. NEUROD1 gene mutations interfere with the maturation of $\beta$-cells and impair their glucose-sensing ability and as a result, their insulin secretion response. Homozygous NEUROD1 gene mutations lead to neonatal diabetes and are associated with neurological abnormalities whereas heterozygous mutations result in childhood- or adultonset diabetes. ${ }^{[7,77]}$

The other types of MODY in this category include MODY7 (KLF11 MODY), which results from the mutations in Kruppel-like factor 11 (KLF11) gene located on chromosome $2 \mathrm{p} 25^{[78]}$ and MODY8 (CEL MODY), which arises from the mutations in carboxyl ester lipase (CEL) gene located on chromosome $9 \mathrm{q} 34 .{ }^{[79]}$ This category also includes MODY9 (PAX4 MODY), caused due to the mutations in PAX family transcription factor, Paired box gene 4 (PAX4) gene located on chromosome $7 \mathrm{q}^{32^{[80]}}$ and MODY10 (INS MODY), which results from the mutations in the INS located on chromosome 11p15 $5^{[81,82]}$; also, MODY11 (BLK MODY), which arises due to the mutations in the human homolog of a B-lymphocyte-specific protein tyrosine kinase (BLK) gene located on chromosome 8p23.1. ${ }^{[83]}$

Furthermore, there is MODY12 (ABCC8-MODY), which results from the mutations in ATP-binding cassette transporter subfamily $\mathrm{C}$ member 8 (ABCC8) gene located on chromosome $11 \mathrm{p} 15$ and $\mathrm{ABCC} 8$ which encodes sulfonylurea receptor-1 (SUR1) protein, a subunit of ATPsensitive potassium (KATP) channel. MODY12 is responsive to sulfonylureas. ${ }^{[84]}$

The remaining types include MODY13 (KCNJ11-MODY) and MODY14 (APPL1-MODY). MODY13 (KCNJ11-MODY) is caused due to the mutations in potassium inwardly rectifying channel subfamily J member 11 (KCNJ11) gene located on chromosome 11p15.1 which encodes $\beta$-cell inward rectifier, BIR (inwardly rectifying potassium channel Kir6.2), a subunit of ATP-sensitive potassium (KATP) channel. ${ }^{[55,86]}$ MODY14 (APPL1-MODY) results from the mutations in Adaptor Protein, Phosphotyrosine Interacting With PH Domain and Leucine Zipper 1 (APPL1) or DCC-interacting protein 13- $\alpha$ (DIP13- $\alpha$ ) gene located on chromosome 3p14.3. ${ }^{[87]}$

\section{Neonatal diabetes mellitus}

Neonatal diabetes mellitus (NDM), also known as earlyonset or congenital diabetes, is the diabetes diagnosed during the first 6 months of life. It is a rare disorder with a global incidence rate of 1 per 500,000-300,000 $(1: 500,000-1: 300,000)^{[88,89]}$ live births; though a study in Italy has reported a higher incidence of 1 per 90,000 
$(1: 90,000) \cdot{ }^{[88]} \mathrm{NDM}$ is predominantly of genetic origin with $80-85 \%$ cases occurring due to monogenic defects and is characterized by severe uncontrolled hyperglycemia along with hypoinsulinemia and requires insulin replacement therapy. ${ }^{[89]}$ The genetic abnormalities lead to $\beta$-cell dysfunction and decreased $\beta$-cell mass due to increased apoptotic or non-apoptotic $\beta$-cell death. These defects also result in developmental abnormalities of pancreas and/ or its islets or in very rare cases their complete absence leading to decreased production and secretion of insulin or hypoinsulinemia and in the latter case an absolute insulin deficiency ${ }^{[90]}$ Neonatal diabetes is highly distinct from early-onset T1DM and differs from it both in the origin and pattern of inborn pancreatic disorder and mostly occurs during the first 6 months of life whereas T1DM mostly develops after 6 months of life. Based largely on the clinical features, NDM can assume either of these two forms: transient neonatal diabetes mellitus (TNDM) and permanent neonatal diabetes mellitus (PNDM).

TNDM is the more common form representing approximately $55-60 \%$ of all cases of neonatal diabetes. It usually resolves within 12-18 months after birth but in a majority of cases, NDM relapses during the later years of life from late childhood to early or late adulthood and presents itself as T2DM, indicating the presence of varying degrees of severity, but persistent $\beta$-cell dysfunction, which leads to possible inadequate insulin secretion and/or insulin resistance. Furthermore, the diabetes may also precipitate under stress conditions such as hormonal changes as observed in puberty or in certain diseases. ${ }^{[89,91]}$ TNDM results most often from the abnormalities in chromosome 6 specifically involving the overexpression of imprinted and paternally expressed genes in the $6 \mathrm{q} 24$ region. This includes the HYMAI (hydatiform mole associated and imprinted) gene, zinc finger protein, ZAC gene, and pituitary adenylate cyclase activating polypeptide-1 (PACAP1) gene. A small percentage of TNDM cases arises from the mutations in the ATP binding cassette subfamily $\mathrm{C}$ member 8 (ABCC8) gene also known as sulfonylurea receptor-1 (SUR1) gene and rarely from the mutations in the potassium voltage-gated channel subfamily J member 11 (KCNJ11 or Kir6.2). ${ }^{[89]}$ Both ABCC8 and KCNJ11genes are functionally linked together as these genes encode for the proteins that constitute the individual subunits of the $\beta$-cell $\mathrm{K}_{\text {ATP }}$ channel. The $\mathrm{K}_{\text {ATP }}$ channel is an eight-subunit ATP-sensitive potassium channel with two types of subunits: four regulatory subunits encoded by ABCC8 (SUR1) gene and four pore-forming subunits encoded by KCNJ11 (Kir6.2) gene. This channel regulates the secretion of insulin from the pancreatic $\beta$-cells, thus providing a direct link with normal glucose homeostasis and its dysregulation in diabetes.
PNDM is the less common form of NDM, which unlike TNDM does not go into remission and persists permanently. PNDM most commonly results from the heterozygous autosomal dominant mutations in the ABCC8 and the KCNJ11 genes encoding, respectively, the SUR1 and Kir6.2 subunits of the $\beta$-cell $\mathrm{K}_{\text {ATP }}$ channel. ${ }^{[9,89]}$ Several mutations identified in the INS also cause PNDM. ${ }^{[9]}$ Besides, this type of neonatal diabetes is associated with several syndromes including the immune-dysregulation, polyendocrinopathy, enteropathy, X-linked (IPEX) syndrome, and WolcottRallison syndrome. IPEX syndrome is an autoimmune disorder that results from the mutations in the FOXP3 gene. The autoimmune disorders that characterize IPEX syndrome include autoimmune enteropathy (an autoimmune disorder of the intestines), dermatitis or eczema (an autoimmune disorder of the skin), and polyendocrinopathy (multiple autoimmune disorders of the endocrine glands, including pancreas and thyroid). ${ }^{[9,89,92]}$ WRS is an autosomal recessive disorder, which results from the mutations in the EIF2AK3 gene. ${ }^{[9,89,93]}$ The main characteristics of this disorder include multiple epiphyseo-metaphyseal dysplasia and hepatic dysfunction. Diabetes is a permanent feature associated with this syndrome and in consanguineous families; WRS has emerged as the most frequent cause of PNDM. ${ }^{[94,95]}$ Clinically, it is not possible to predict whether a particular neonatal dysfunction of glucose homeostasis will eventually develop into TNDM or PNDM, which makes the correct diagnosis, and the assessment of the underlying cause of the disorder including the genetic factors involved, an important aspect in the management of this disorder.

Besides MODY and NDM, there are several other monogenic defects in $\beta$-cell function which result in DM. These include the point mutations in mitochondrial DNA such as 3243A$\mathrm{G}$ mutation in the mitochondrial transfer RNA leucine-1 (MTTL1) gene, which leads to deafness and diabetes ${ }^{[96]}$ and the autosomal dominant mutations, which result in a total inability or abnormal conversion of proinsulin to insulin. ${ }^{[97]}$ Furthermore, it also includes the mutations that lead to the production of structurally abnormal insulin molecules with impaired receptor binding.

Diabetes caused due to genetic abnormalities in insulin action

Several genetic abnormalities in insulin action resulting either from insulin receptor functional impairment or decrease in the number of insulin receptors, caused mainly due to the mutations in insulin receptor (INSR) gene located on chromosome 19, have been identified. These abnormalities in insulin action lead to hyperinsulinemia or insulin resistance and subsequent mild to modest hyperglycemia or may even cause severe hyperglycemia 
characteristic of overt diabetes. ${ }^{[1]}$ The various forms of diabetes resulting from the abnormalities in insulin action, often described as inherited severe insulin resistance syndromes, include type A insulin resistance syndrome, lipoatrophic diabetes, Donohue syndrome (leprechaunism), and Rabson-Mendenhall syndrome (RMS).

Type A insulin resistance syndrome results from mutations in INSR gene. This syndrome is associated with menstruation disorders (primary amenorrhea or oligomenorrhea) and specific forms of polycystic ovarian syndrome characterized by hirsutism due to hyperandrogenism and multiple enlarged cysts on the ovaries, in females ${ }^{[98]}$; also, acanthosis nigricans, a skin pigmentation disorder, most often in females than in males ${ }^{[99]}$ and obesity, ${ }^{[100]}$ most often in males than in females and severe insulin resistance.

Lipoatrophic diabetes is a monogenic but heterogeneous insulin resistance syndrome associated with lipoatrophy and lipodystrophy and characterized by paucity (insufficiency) of fat, insulin resistance, and dyslipidemia, more specifically, hypertriglyceridemia. ${ }^{[101]}$ Lipoatrophic diabetes arises due to the mutations in several different genes, which manifests as different genetic syndromes. It may result from the mutations in Laminin A/C (LMNA) gene located on chromosome 1q21-22 and manifest as an autosomal dominant disorder known as familial partial lipoatrophy, also known as Dunnigan or Koberling-Dunnigan syndrome. ${ }^{[102]}$ Lipoatrophic diabetes may also result from the mutations, either in the AGPAT2 gene or in the BSCL2 gene. AGPAT2 gene located on chromosome 9q34 encodes the enzyme 1-acyl-sn-glycerol-3-phosphate$\mathrm{D}$-acetyltransferase-2, which is involved in triglyceride synthesis. Berardinelli-Seip congenital lipodystrophy type-2 (BSCL2) gene, also known as $\gamma 3$-linked gene (GNG3) or seipin gene, located on chromosome 11q13 encodes seipin, an endoplasmic reticulum-associated protein involved in lipid droplet biogenesis. Both these mutations manifest as an autosomal recessive disorder known as Congenital generalized lipoatrophy or Berardinelli-Seip syndrome. ${ }^{[103,104]}$

Furthermore, the mutations in insulin receptor gene may also lead to the Donohue syndrome (leprechaunism) and the RMS, both of which manifest in infancy, and diabetes in these syndromes is characterized by strong insulin resistance and severe hyperglycemia. ${ }^{[105]}$

\section{Endocrinopathies}

Several endocrinopathies resulting in or from abnormal functioning of various hormones can lead to diabetes. These include the endocrinopathies that involve the hyperactivity of those hormones which partly or fully antagonize the function of insulin such as Cushing syndrome, acromegaly, pheochromocytoma, glucagonoma, and hyperthyroidism, which result from hyperactivity of cortisol, growth hormone, norepinephrine (and epinephrine), glucagon, and thyroid hormones, respectively. Diabetes associated with these endocrine disorders usually occurs when a defect in insulin secretion and/or action is already present. ${ }^{[106,107]}$ Some endocrinopathies induce diabetes through inhibition of insulin secretion and these include somatostatinoma, which leads to the excessive secretion of somatostatin and primary hyperaldosteronism ${ }^{[108]}$ or Conn's syndrome induced hypokalemia, which involves the hypersecretion and hyperactivity of the hormone, aldosterone. ${ }^{[109]}$ Diabetes caused due to various endocrinopathies usually resolves when endocrinopathies are treated or managed.

\section{Exocrine pancreatic pathologies}

Several diseases of the exocrine pancreas have been found to cause diabetes but the contribution of these diseases to the overall incidence of diabetes is minimal with less than $0.5 \%$ of all the cases of diabetes resulting from the diseases of the exocrine pancreas. These include chronic pancreatitis (fibrocalculous pancreatopathy), trauma (pancreatectomy), infection, hereditary hemochromatosis, secondary hemochromatosis, cystic fibrosis, and pancreatic neoplasia (adenocarcinoma and glucagonoma). ${ }^{[110-112]}$ All these pancreatic pathologies, with the exception of pancreatic neoplasia, lead to diabetes only when they are severe enough to cause extensive pancreatic damage, involving the endocrine pancreas, including the islets of Langerhans, which leads to a considerable reduction in the $\beta$-cell mass and impairment of $\beta$-cell function. ${ }^{[113]}$ The pancreatic neoplasia-associated diabetes occurs even without any reduction in $\beta$-cell mass. ${ }^{[1]}$

\section{Infections}

Several infections caused by viruses are known to cause $\beta$-cell dysfunction, mainly through $\beta$-cell destruction, and lead to hyperglycemia, which gradually presents as overt diabetes. These include infections caused by cytomegalovirus, adenovirus, Coxsackie virus B, and mumps. Besides, congenital rubella syndrome, caused by rubella virus, has also been closely linked with diabetes, but this diabetes in most of the cases is associated with the presence of HLA and other immune markers, which are characteristic of T1DM..$^{[1,114,115]}$ Furthermore, insulin resistance has been associated with chronic hepatitis $\mathrm{C}$ virus infection and progression of fibrosis and a very high prevalence of T2DM has been reported among the individuals infected with the hepatitis C virus. ${ }^{[116,117]}$ 


\section{Drug- or chemical-induced}

Several drugs and chemicals are known to induce diabetes. These agents induce diabetes either through the impairment of insulin production or secretion, which mainly results from the destruction of $\beta$-cells or through a decrease in the sensitivity of tissues to insulin, which causes insulin resistance. Diabetes resulting from the drug- or chemical-induced increase in insulin resistance occurs only in susceptible individuals. Furthermore, these agents may worsen or increase the severity of hyperglycemia in individuals with already existing overt diabetes. The drugs and chemicals known to induce diabetes include glucocorticoids, diazoxide, thiazides, $\beta_{2}$-receptor agonists (salbutamol and ritodrine), nonselective $\beta$-adrenergic antagonists, dilantin, hormones including growth hormone (in very high doses), thyroid hormone (thyroxine/triiodothyronine), somatostatin, estradiol, levonorgestrel, and glucagon. These also include $\gamma$-interferon, protease inhibitors (indinavir, nelfinavir, ritonavir, and saquinavir), nicotinic acid, and $\beta$-cell toxins including streptozocin (streptozotocin), cyclosporine, rodenticide vacor and pentamidine, and several antipsychotics. ${ }^{[118,119]}$ Furthermore, immune checkpoint inhibitors, such as ipilimumab, nivolumab, and pembrolizumab, used in cancer immunotherapy for treatment of advanced-stage cancers, including head and neck cancer, renal cancer, urothelial cancers, non-small-cell lung carcinoma, and melanoma besides other cancers ${ }^{[120-125]}$ have been reported to induce new-onset T1DM, through immune-mediated $\beta$-islet cell dysfunction. ${ }^{[125,126]}$

\section{Other genetic syndromes associated with diabetes} There are many others, besides the already mentioned genetic syndromes, that are usually associated with an increased incidence of diabetes. These include Down's syndrome, Turner's syndrome, Wolfram's syndrome, Klinefelter's syndrome, Huntington's chorea, Friedreich's ataxia, myotonic dystrophy, Laurence-Moon-Biedl syndrome, Porphyria, and Prader-Willi syndrome among others. ${ }^{[127]}$

\section{Uncommon forms of immune-mediated diabetes}

The uncommon forms of immune-mediated diabetes are very rare in occurrence and mainly include diabetes associated with Moersch-Woltman syndrome (stiff-person syndrome [SPS]), anti-insulin receptor antibodies (AIRAs), and insulin autoimmune syndrome (IAS; Hirata's disease).

Moersch-Woltman syndrome or the SPS is a very rare autoimmune disorder that affects the central nervous system and is characterized by progressive fluctuating rigidity of the axial muscles (muscles of the trunk and head), accompanied by painful muscle spasms. Patients with SPS generally present with high titers of GADAs and are frequently associated with various diseases including pernicious anemia, thyroiditis, vitiligo, and type 1-like diabetes. Although GADAs are detected in most of the individuals with T1DM alone; but the individuals with SPS with or without diabetes have 50-100 times more titers of GADAs. $^{[128]}$

The AIRAs are often associated with various autoimmune diseases, including primary biliary cholangitis, systemic lupus erythematosus, and Hashimoto thyroiditis. AIRAs generally bind to insulin receptors on various insulin target tissues, which block the binding of insulin to these receptors and hence the subsequent signaling pathways. This leads to diabetes characterized by a rapidly progressive and extreme form of insulin resistance, earlier termed as type B insulin resistance. Alternatively, AIRAs once bound to target receptors may sometimes cause spontaneous hyperinsulinemic hypoglycemia by acting as insulin agonists. Diabetes associated with AIRAs is often characterized by acanthosis nigricans and impaired insulin degradation. ${ }^{[129,130]}$

IAS or Hirata's disease is described as a condition, which is characterized by the presence of autoantibodies to the endogenous insulin (IAA) in the absence of any previous exposure to the exogenous insulin, absence of any pathological abnormalities of the pancreatic islets and presents as endogenous hyperinsulinemia hypoglycemia. Although, the predisposition to this condition is present from birth, but the overt disease most often presents itself during adulthood and can be triggered by exposure to certain drugs and viruses. IAS can be controlled through simple dietary management. ${ }^{[131]}$

\section{Ketosis-prone diabetes mellitus}

Ketosis-prone diabetes mellitus (KPD) describes another heterogeneous group of diabetes, which like T2DM, characteristically does not involve the immune-mediated destruction of pancreatic $\beta$-cells but unlike T2DM, this type presents with frequent episodes of DKA or unprovoked ketosis. ${ }^{[132]}$ KPD occurs most frequently in African Americans and Africans in sub-Saharan Africa but has now been observed increasingly in Hispanic, Chinese, and Japanese populations. ${ }^{[132-135]}$ One of the best described subtypes of this diabetes is Flatbush diabetes which along with characteristic episodic DKA is frequently associated with HLA-DR3 and/or HLA-DR4 haplotypes. ${ }^{[136]}$ The patients with KPD show periodic but absolute requirement of insulin replacement therapy, concomitant with the episodes of DKA and outside of the frequent episodes of DKA, the diabetes can be controlled through simple diet management without insulin replacement therapy. 


\section{CONCLUSIONS}

DM is a heterogeneous metabolic disease, represented by diverse forms, each with a distinct pathophysiological origin but often manifest as a disorder with overlapping and difficult-to-differentiate characteristics. The treatment and management of each of these diabetic types are distinct in some characteristics but share a great deal of similarity as well as is the case with the disorder itself. All this emphasizes the importance of correct and timely diagnosis of each of these diabetic types and the critical role of their pathophysiological understanding. This is vital to safeguard diabetic individuals from exposures to potential adverse effects of improper, ineffective, or avoidable pharmaceutical interventions, which often delays the desired prognosis and increases the duration of hyperglycemic exposures. The long-term hyperglycemia, in turn, has often been associated with increased risk of microvascular and macrovascular diabetic complications, which affect the quality of life and mainly contribute to the diabetes-associated morbidity and mortality. For diabetes in general, and in particular, the diabetes types resulting from genetic mutations or associated genetic anomalies, the correct and timely molecular diagnosis can help in disease risk analysis and help in disease prediction and timely identification of individuals at an increased risk to the disorder, in particular, the family members. The predictive molecular/genetic testing and preventive management can play a vital role in such cases. Furthermore, irrespective of the diabetes type, various lifestyle modifications and interventions such as extensive diet control, physical exercises, change of daily sedentary routine, and control of obesity are important in the prevention and the management of diabetes. The educational campaigns, which make the general population aware of the pathogenesis of this disease and the various controllable risk factors associated with it, are also a vital tool in the management and control of diabetes mellitus.

\section{Financial support and sponsorship}

Nil.

\section{Conflict of interest}

The contributing authors have no financial or nonfinancial competing interests.

\section{References}

1. American Diabetes Association. Diagnosis and classification of diabetes mellitus. Diabetes Care 2014;37:S81-90.

2. American Diabetes Association. Introduction: Standards of medical care in diabetes-2018. Diabetes Care 2018;41:S1-2.

3. American Diabetes Association. Microvascular complications and foot care: Standards of medical care in diabetes-2018. Diabetes Care 2018;41:S105-18.
4. American Diabetes Association. Cardiovascular disease and risk management: Standards of medical care in diabetes-2018. Diabetes Care 2018;41:S86-104.

5. Rawshani A, Rawshani A, Franzén S, Eliasson B, Svensson AM, Miftaraj M, et al. Mortality and cardiovascular disease in type 1 and type 2 diabetes. N Engl J Med 2017;376:1407-18.

6. Blas E, Kuru A, editors. Diabetes: Equity and social determinants. In: Equity, Social Determinants and Public Health Programmes. Geneva, Switzerland: World Health Organization; 2010.

7. Saeedi P, Petersohn I, Salpea P, Malanda B, Karuranga S, Unwin N, et al.; IDF Diabetes Atlas Committee. Global and regional diabetes prevalence estimates for 2019 and projections for 2030 and 2045: Results from the international diabetes federation diabetes atlas, $9^{\text {th }}$ edition. Diabetes Res Clin Pract 2019;157:107843.

8. International Diabetes Federation. IDF Diabetes Atlas. 9th ed. Brussels, Belgium: International Diabetes Federation; 2019.

9. American Diabetes Association. Classification and diagnosis of diabetes: Standards of medical care in diabetes—2018. Diabetes Care 2018;41:S13-27.

10. Knip M, Siljander H. Autoimmune mechanisms in type 1 diabetes. Autoimmun Rev 2008;7:550-7.

11. Kahaly GJ, Hansen MP. Type 1 diabetes associated autoimmunity. Autoimmun Rev 2016;15:644-8.

12. Taplin CE, Barker JM. Autoantibodies in type 1 diabetes. Autoimmunity 2008;41:11-8.

13. Lahtela JT, Knip M, Paul R, Antonen J, Salmi J. Severe antibody-mediated human insulin resistance: Successful treatment with the insulin analog lispro. A case report. Diabetes Care 1997;20:71-3.

14. Matsuyoshi A, Shimoda S, Tsuruzoe K, Taketa K, Chirioka T, Sakamoto F, et al. A case of slowly progressive type 1 diabetes with unstable glycemic control caused by unusual insulin antibody and successfully treated with steroid therapy. Diabetes Res Clin Pract 2006;72:238-43.

15. Zimmet PZ, Tuomi T, Mackay IR, Rowley MJ, Knowles W, Cohen M, et al. Latent autoimmune diabetes mellitus in adults [LADA]: The role of antibodies to glutamic acid decarboxylase in diagnosis and prediction of insulin dependency. Diabet Med 1994;11:299-303.

16. Naik RG, Palmer JP. Latent autoimmune diabetes in adults (LADA). Rev Endocr Metab Disord 2003;4:233-41.

17. Lampasona V, Petrone A, Tiberti C, Capizzi M, Spoletini M, di Pietro S, et al.; Non Insulin Requiring Autoimmune Diabetes (NIRAD) Study Group. Zinc transporter 8 antibodies complement GAD and IA-2 antibodies in the identification and characterization of adult-onset autoimmune diabetes: Non insulin requiring autoimmune diabetes (NIRAD) 4. Diabetes Care 2010;33:104-8.

18. Hawa MI, Kolb H, Schloot N, Beyan H, Paschou SA, Buzzetti R, et al.; Action LADA Consortium. Adult-onset autoimmune diabetes in Europe is prevalent with a broad clinical phenotype: Action LADA 7. Diabetes Care 2013;36:908-13.

19. Hughes JW, Riddlesworth TD, DiMeglio LA, Miller KM, Rickels MR, McGill JB; T1D Exchange Clinic Network. Autoimmune diseases in children and adults with type 1 diabetes from the T1D exchange clinic registry. J Clin Endocrinol Metab 2016;101:4931-7.

20. Triolo TM, Armstrong TK, McFann K, Yu L, Rewers MJ, Klingensmith GJ, et al. Additional autoimmune disease found in $33 \%$ of patients at type 1 diabetes onset. Diabetes Care 2011;34:1211-3.

21. Wellcome Trust Case Control Consortium. Genome-wide association study of 14,000 cases of seven common diseases and 3,000 shared controls. Nature 2007;447:661-78.

22. Todd JA, Walker NM, Cooper JD, Smyth DJ, Downes K, Plagnol V, et al.; Genetics of Type 1 Diabetes in Finland; Wellcome Trust Case Control Consortium. Robust associations of four new chromosome regions from genome-wide analyses of type 1 diabetes. Nat Genet 2007;39:857-64.

23. Undlien DE, Lie BA, Thorsby E. HLA complex genes in type 1 diabetes and other autoimmune diseases. Which genes are involved? Trends Genet 2001;17:93-100. 
24. Park Y. Functional evaluation of the type 1 diabetes (T1D) susceptibility candidate genes. Diabetes Res Clin Pract 2007;77:S110-5.

25. Chistiakov DA, Voronova NV, Chistiakov PA. The crucial role of IL-2/ IL-2RA-mediated immune regulation in the pathogenesis of type 1 diabetes, an evidence coming from genetic and animal model studies. Immunol Lett 2008;118:1-5.

26. Imagawa A, Hanafusa T, Miyagawa J, Matsuzawa Y. A novel subtype of type 1 diabetes mellitus characterized by a rapid onset and an absence of diabetes-related antibodies. Osaka IDDM Study Group. N Engl J Med 2000;342:301-7.

27. Leahy JL. Pathogenesis of type 2 diabetes mellitus. Arch Med Res 2005;36:197-209.

28. DeFronzo RA. Pathogenesis of type 2 diabetes mellitus. Med Clin North Am 2004;88:787-835, ix.

29. Muoio DM, Newgard CB. Mechanisms of disease:molecular and metabolic mechanisms of insulin resistance and beta-cell failure in type 2 diabetes. Nat Rev Mol Cell Biol 2008;9:193-205.

30. Umpierrez G, Korytkowski M. Diabetic emergencies—ketoacidosis, hyperglycaemic hyperosmolar state and hypoglycaemia. Nat Rev Endocrinol 2016;12:222-32.

31. Fadini GP, Bonora BM, Avogaro A. SGLT2 inhibitors and diabetic ketoacidosis: Data from the FDA adverse event reporting system. Diabetologia 2017;60:1385-9.

32. Frayling TM. Genome-wide association studies provide new insights into type 2 diabetes aetiology. Nat Rev Genet 2007;8:657-62.

33. Zeggini E, Scott LJ, Saxena R, Voight BF, Marchini JL, Hu T, et al.; Wellcome Trust Case Control Consortium. Meta-analysis of genomewide association data and large-scale replication identifies additional susceptibility loci for type 2 diabetes. Nat Genet 2008;40:638-45.

34. Fujimoto WY. The importance of insulin resistance in the pathogenesis of type 2 diabetes mellitus. Am J Med 2000;108:9S-14S.

35. Kahn SE, Hull RL, Utzschneider KM. Mechanisms linking obesity to insulin resistance and type 2 diabetes. Nature 2006;444:840-6.

36. Lawrence JM, Contreras R, Chen W, Sacks DA. Trends in the prevalence of preexisting diabetes and gestational diabetes mellitus among a racially/ethnically diverse population of pregnant women, 1999-2005. Diabetes Care 2008;31:899-904.

37. Yuen L, Wong VW. Gestational diabetes mellitus: Challenges for different ethnic groups. World J Diabetes 2015;6:1024-32.

38. Hedderson MM, Darbinian JA, Ferrara A. Disparities in the risk of gestational diabetes by race-ethnicity and country of birth. Paediatr Perinat Epidemiol 2010;24:441-8.

39. Cosson E. Diagnostic criteria for gestational diabetes mellitus. Diabetes Metab 2010;36:538-48.

40. Kim C. Gestational diabetes: Risks, management, and treatment options. Int J Womens Health 2010;2:339-51.

41. Noctor E, Crowe C, Carmody LA, Saunders JA, Kirwan B, O'Dea A, et al.; ATLANTIC-DIP Investigators. Abnormal glucose tolerance postgestational diabetes mellitus as defined by the international association of diabetes and pregnancy study groups criteria. Eur J Endocrinol 2016;175:287-97.

42. Kim C, Newton KM, Knopp RH. Gestational diabetes and the incidence of type 2 diabetes: A systematic review. Diabetes Care 2002;25:1862-8.

43. Aroda VR, Christophi CA, Edelstein SL, Zhang P, Herman WH, BarrettConnor E, et al.; Diabetes Prevention Program Research Group. The effect of lifestyle intervention and metformin on preventing or delaying diabetes among women with and without gestational diabetes: The Diabetes Prevention Program outcomes study 10-year follow-up. J Clin Endocrinol Metab 2015;100:1646-53.

44. Gardner DS, Tai ES. Clinical features and treatment of maturity onset diabetes of the young [MODY]. Diabetes Metab Syndr Obes 2012;5:101-8.

45. Shields BM, Hicks S, Shepherd MH, Colclough K, Hattersley AT, Ellard S. Maturity-onset diabetes of the young (MODY): How many cases are we missing? Diabetologia 2010;53:2504-8.
46. Kim SH. Maturity-onset diabetes of the young: What do clinicians need to know? Diabetes Metab J 2015;39:468-77.

47. Hattersley AT, Greeley SAW, Polak M, Rubio-Cabezas O, Njølstad PR, Mlynarski W, et al. ISPAD clinical practice consensus guidelines 2018: The diagnosis and management of monogenic diabetes in children and adolescents. Pediatr Diabetes 2018;19:47-63.

48. Vaxillaire M, Froguel P. Monogenic diabetes in the young, pharmacogenetics and relevance to multifactorial forms of type 2 diabetes. Endocr Rev 2008;29:254-64.

49. Froguel P, Velho G. Molecular genetics of maturity-onset diabetes of the young. Trends Endocrinol Metab 1999;10:142-6.

50. García-Herrero CM, Rubio-Cabezas O, Azriel S, Gutierrez-Nogués A, Aragonés A, Vincent $\mathrm{O}$, et al. Functional characterization of MODY2 mutations highlights the importance of the fine-tuning of glucokinase and its role in glucose sensing. PLoS One 2012;7:e30518.

51. Yamagata K, Oda N, Kaisaki PJ, Menzel S, Furuta H, Vaxillaire M, et al. Mutations in the hepatocyte nuclear factor-1alpha gene in maturityonset diabetes of the young (MODY3). Nature 1996;384:455-8.

52. Glaser B, Kesavan P, Heyman M, Davis E, Cuesta A, Buchs A, et al. Familial hyperinsulinism caused by an activating glucokinase mutation. $\mathrm{N}$ Engl J Med 1998;338:226-30.

53. Matschinsky F, Liang Y, Kesavan P, Wang L, Froguel P, Velho G, et al. Glucokinase as pancreatic beta cell glucose sensor and diabetes gene. J Clin Invest 1993;92:2092-8.

54. Osbak KK, Colclough K, Saint-Martin C, Beer NL, BellannéChantelot C, Ellard S, et al. Update on mutations in glucokinase (GCK), which cause maturity-onset diabetes of the young, permanent neonatal diabetes, and hyperinsulinemic hypoglycemia. Hum Mutat 2009;30:1512-26.

55. Colclough K, Bellanne-Chantelot C, Saint-Martin C, Flanagan SE, Ellard S. Mutations in the genes encoding the transcription factors hepatocyte nuclear factor 1 alpha and 4 alpha in maturity-onset diabetes of the young and hyperinsulinemic hypoglycemia. Hum Mutat 2013;34:669-85.

56. Bacon S, Kyithar MP, Schmid J, Rizvi SR, Bonner C, Graf R, et al. Serum levels of pancreatic stone protein (PSP)/reg1a as an indicator of beta-cell apoptosis suggest an increased apoptosis rate in hepatocyte nuclear factor 1 alpha (HNF1A-MODY) carriers from the third decade of life onward. BMC Endocr Disord 2012;12:13.

57. Stoffel M, Duncan SA. The maturity-onset diabetes of the young [MODY1] transcription factor HNF4 $\alpha$ regulates expression of genes required for glucose transport and metabolism. Proc Natl Acad Sci U S A 1997;94:13209-14.

58. Gupta RK, Vatamaniuk MZ, Lee CS, Flaschen RC, Fulmer JT, Matschinsky FM, et al. The MODY1 gene HNF-4alpha regulates selected genes involved in insulin secretion. J Clin Invest 2005;115:1006-15.

59. Shepherd M, Shields B, Ellard S, Rubio-Cabezas O, Hattersley AT. A genetic diagnosis of HNF1A diabetes alters treatment and improves glycaemic control in the majority of insulin-treated patients. Diabet Med 2009;26:437-41.

60. Pearson ER, Starkey BJ, Powell RJ, Gribble FM, Clark PM, Hattersley AT. Genetic cause of hyperglycaemia and response to treatment in diabetes. Lancet 2003;362:1275-81.

61. Edghill EL, Bingham C, Ellard S, Hattersley AT. Mutations in hepatocyte nuclear factor-1beta and their related phenotypes. J Med Genet 2006;43:84-90.

62. Horikawa Y, Iwasaki N, Hara M, Furuta H, Hinokio Y, Cockburn BN, et al. Mutation in hepatocyte nuclear factor-1 beta gene (TCF2) associated with MODY. Nat Genet 1997;17:384-5.

63. Barbacci E, Reber M, Ott MO, Breillat C, Huetz F, Cereghini S. Variant hepatocyte nuclear factor 1 is required for visceral endoderm specification. Development 1999;126:4795-805.

64. Bingham C, Ellard S, Allen L, Bulman M, Shepherd M, Frayling T, et al. Abnormal nephron development associated with a frameshift mutation 
in the transcription factor hepatocyte nuclear factor- 1 beta. Kidney Int 2000;57:898-907.

65. Bingham C, Bulman MP, Ellard S, Allen LI, Lipkin GW, Hoff WG, et al. Mutations in the hepatocyte nuclear factor-1beta gene are associated with familial hypoplastic glomerulocystic kidney disease. Am J Hum Genet 2001;68:219-24.

66. Edghill EL, Bingham C, Slingerland AS, Minton JA, Noordam C, Ellard S, et al. Hepatocyte nuclear factor- 1 beta mutations cause neonatal diabetes and intrauterine growth retardation: Support for a critical role of HNF-1beta in human pancreatic development. Diabet Med 2006;23:1301-6.

67. Bellanné-Chantelot C, Chauveau D, Gautier JF, Dubois-Laforgue D, Clauin S, Beaufils S, et al. Clinical spectrum associated with hepatocyte nuclear factor-1 beta mutations. Ann Intern Med 2004;140:510-7.

68. Kavvoura FK, Owen KR. Maturity onset diabetes of the young: Clinical characteristics, diagnosis and management. Pediatr Endocrinol Rev 2012;10:234-42.

69. Bingham C, Ellard S, van't Hoff WG, Simmonds HA, Marinaki AM, Badman MK, et al. Atypical familial juvenile hyperuricemic nephropathy associated with a hepatocyte nuclear factor-1 beta gene mutation. Kidney Int 2003;63:1645-51.

70. Stoffers DA, Ferrer J, Clarke WL, Habener JF. Early-onset type-II diabetes mellitus (MODY4) linked to IPF1. Nat Genet 1997;17:138-9.

71. Stoffers DA, Thomas MK, Habener JF. Homeodomain protein IDX1: A master regulator of pancreas development and insulin gene expression. Trends Endocrinol Metab 1997;8:145-51.

72. Kim SK, Selleri L, Lee JS, Zhang AY, Gu X, Jacobs Y, et al. Pbx1 inactivation disrupts pancreas development and in Ipf1-deficient mice promotes diabetes mellitus. Nat Genet 2002;30:430-5.

73. Schwitzgebel VM, Mamin A, Brun T, Ritz-Laser B, Zaiko M, Maret A, et al. Agenesis of human pancreas due to decreased half-life of insulin promoter factor 1. J Clin Endocrinol Metab 2003;88:4398-406.

74. Ahlgren U, Jonsson J, Jonsson L, Simu K, Edlund H. Beta-cell-specific inactivation of the mouse Ipf1/Pdx1 gene results in loss of the beta-cell phenotype and maturity onset diabetes. Genes Dev 1998;12:1763-8.

75. Malecki MT, Jhala US, Antonellis A, Fields L, Doria A, Orban T, et al. Mutations in NEUROD1 are associated with the development of type 2 diabetes mellitus. Nat Genet 1999;23:323-8.

76. Gonsorcíková L, Průhová S, Cinek O, Ek J, Pelikánová T, Jørgensen T, et al. Autosomal inheritance of diabetes in two families characterized by obesity and a novel $\mathrm{H} 241 \mathrm{Q}$ mutation in NEUROD1. Pediatr Diabetes 2008;9:367-72.

77. Rubio-Cabezas O, Minton JA, Kantor I, Williams D, Ellard S, Hattersley AT. Homozygous mutations in NEUROD1 are responsible for a novel syndrome of permanent neonatal diabetes and neurological abnormalities. Diabetes 2010;59:2326-31.

78. Lomberk G, Grzenda A, Mathison A, Escande C, Zhang JS, Calvo E, et al. Krüppel-like factor 11 regulates the expression of metabolic genes via an evolutionarily conserved protein interaction domain functionally disrupted in maturity onset diabetes of the young. J Biol Chem 2013;288:17745-58.

79. Raeder H, Johansson S, Holm PI, Haldorsen IS, Mas E, Sbarra V, et al. Mutations in the CEL VNTR cause a syndrome of diabetes and pancreatic exocrine dysfunction. Nat Genet 2006;38:54-62.

80. Biason-Lauber A, Boehm B, Lang-Muritano M, Gauthier BR, Brun T, Wollheim CB, et al. Association of childhood type 1 diabetes mellitus with a variant of PAX4: Possible link to beta cell regenerative capacity. Diabetologia 2005;48:900-5.

81. Molven A, Ringdal M, Nordbø AM, Raeder H, Støy J, Lipkind GM, et al.; Norwegian Childhood Diabetes Study Group. Mutations in the insulin gene can cause MODY and autoantibody-negative type 1 diabetes. Diabetes 2008;57:1131-5.

82. Edghill EL, Flanagan SE, Patch AM, Boustred C, Parrish A, Shields B, et al.; Neonatal Diabetes International Collaborative Group. Insulin mutation screening in 1,044 patients with diabetes: Mutations in the INS gene are a common cause of neonatal diabetes but a rare cause of diabetes diagnosed in childhood or adulthood. Diabetes 2008;57:1034-42.

83. Borowiec M, Liew CW, Thompson R, Boonyasrisawat W, Hu J, Mlynarski WM, et al. Mutations at the BLK locus linked to maturity onset diabetes of the young and beta-cell dysfunction. Proc Natl Acad Sci U S A 2009;106:14460-5.

84. Bowman P, Flanagan SE, Edghill EL, Damhuis A, Shepherd MH, Paisey R, et al. Heterozygous ABCC8 mutations are a cause of MODY. Diabetologia 2012;55:123-7.

85. Gloyn AL, Cummings EA, Edghill EL, Harries LW, Scott R, Costa T, et al. Permanent neonatal diabetes due to paternal germline mosaicism for an activating mutation of the KCNJ11 gene encoding the kir6.2 subunit of the beta-cell potassium adenosine triphosphate channel. J Clin Endocrinol Metab 2004;89:3932-5.

86. Yorifuji T, Nagashima K, Kurokawa K, Kawai M, Oishi M, Akazawa Y, et al. The C42R mutation in the kir6.2 (KCNJ11) gene as a cause of transient neonatal diabetes, childhood diabetes, or later-onset, apparently type 2 diabetes mellitus. J Clin Endocrinol Metab 2005;90:3174-8.

87. Prudente S, Jungtrakoon P, Marucci A, Ludovico O, Buranasupkajorn P, Mazza T, et al. Loss-of-function mutations in APPL1 in familial diabetes mellitus. Am J Hum Genet 2015;97:177-85.

88. Iafusco D, Massa O, Pasquino B, Colombo C, lughetti L, Bizzarri C, et al.; Early Diabetes Study Group of ISPED. Minimal incidence of neonatal/ infancy onset diabetes in Italy is 1:90,000 live births. Acta Diabetol 2012;49:405-8.

89. Polak M, Cavé H. Neonatal diabetes mellitus: A disease linked to multiple mechanisms. Orphanet J Rare Dis 2007;2:12.

90. Aguilar-Bryan L, Bryan J. Neonatal diabetes mellitus. Endocr Rev 2008;29:265-91.

91. von Mühlendahl KE, Herkenhoff H. Long-term course of neonatal diabetes. N Engl J Med 1995;333:704-8.

92. Bennett $\mathrm{CL}$, Christie J, Ramsdell F, Brunkow ME, Ferguson PJ, Whitesell $\mathrm{L}$, et al. The immune dysregulation, polyendocrinopathy, enteropathy, X-linked syndrome (IPEX) is caused by mutations of FOXP3. Nat Genet 2001;27:20-1.

93. Delépine M, Nicolino M, Barrett T, Golamaully M, Lathrop GM, Julier C. EIF2AK3, encoding translation initiation factor 2-alpha kinase 3, is mutated in patients with Wolcott-Rallison syndrome. Nat Genet 2000;25:406-9.

94. Ozbek MN, Senée V, Aydemir S, Kotan LD, Mungan NO, Yuksel B, et al. Wolcott-Rallison syndrome due to the same mutation (W522X) in EIF2AK3 in two unrelated families and review of the literature. Pediatr Diabetes 2010;11:279-85.

95. Rubio-Cabezas O, Patch AM, Minton JA, Flanagan SE, Edghill EL, Hussain K, et al.; Neonatal Diabetes International Collaborative Group. Wolcott-Rallison syndrome is the most common genetic cause of permanent neonatal diabetes in consanguineous families. J Clin Endocrinol Metab 2009;94:4162-70.

96. Kadowaki T, Kadowaki H, Mori Y, Tobe K, Sakuta R, Suzuki Y, et al. A subtype of diabetes mellitus associated with a mutation of mitochondrial DNA. N Engl J Med 1994;330:962-8.

97. Gruppuso PA, Gorden P, Kahn CR, Cornblath M, Zeller WP, Schwartz R. Familial hyperproinsulinemia due to a proposed defect in conversion of proinsulin to insulin. N Engl J Med 1984;311:629-34.

98. Diamanti-Kandarakis E, Dunaif A. Insulin resistance and the polycystic ovary syndrome revisited: An update on mechanisms and implications. Endocr Rev 2012;33:981-1030.

99. Kahn CR, Flier JS, Bar RS, Archer JA, Gorden P, Martin MM, et al. The syndromes of insulin resistance and acanthosis nigricans. Insulinreceptor disorders in man. N Engl J Med 1976;294:739-45.

100. Taylor SI. Lilly lecture: Molecular mechanisms of insulin resistance. Lessons from patients with mutations in the insulin-receptor gene. Diabetes 1992;41:1473-90. 
101. Garg A. Lipodystrophies. Am J Med 2000;108:143-52.

102. Vigouroux C, Magré J, Vantyghem MC, Bourut C, Lascols O, Shackleton S, et al. Lamin $\mathrm{A} / \mathrm{C}$ gene: Sex-determined expression of mutations in dunnigan-type familial partial lipodystrophy and absence of coding mutations in congenital and acquired generalized lipoatrophy. Diabetes 2000;49:1958-62.

103. Garg A. Acquired and inherited lipodystrophies. N Engl J Med 2004;350:1220-34.

104. Magré J, Delépine M, Khallouf E, Gedde-Dahl T Jr, Van Maldergem L, Sobel E, et al. Identification of the gene altered in Berardinelli-Seip congenital lipodystrophy on chromosome 11q13. Nature Genetics 2001;28:365-70.

105. Krook A, Kumar S, Laing I, Boulton AJ, Wass JA, O'Rahilly S. Molecular scanning of the insulin receptor gene in syndromes of insulin resistance. Diabetes 1994;43:357-68.

106. Resmini E, Minuto F, Colao A, Ferone D. Secondary diabetes associated with principal endocrinopathies: The impact of new treatment modalities. Acta Diabetol 2009;46:85-95.

107. Biering H, Knappe G, Gerl H, Lochs H. [Prevalence of diabetes in acromegaly and Cushing syndrome]. Acta Med Austriaca 2000;27:27-31.

108. Krejs GJ, Orci L, Conlon JM, Ravazzola M, Davis GR, Raskin P, et al. Somatostatinoma syndrome. Biochemical, morphologic and clinical features. N Engl J Med 1979;301:285-92.

109. Nestler JE, McClanahan MA. Diabetes and adrenal disease. Baillieres Clin Endocrinol Metab 1992;6:829-47.

110. Price S, Cole D, Alcolado JC. Diabetes due to exocrine pancreatic disease- a review of patients attending a hospital-based diabetes clinic. QJ Med 2010;103:759-63.

111. Bartosch-Härlid A, Andersson R. Diabetes mellitus in pancreatic cancer and the need for diagnosis of asymptomatic disease. Pancreatology 2010;10:423-8.

112. Frohnert BI, Ode KL, Moran A, Nathan BM, Laguna T, Holme B, et al. Impaired fasting glucose in cystic fibrosis. Diabetes Care 2010;33:2660-4.

113. Williams JA, Goldfine ID. The insulin-pancreatic acinar axis. Diabetes 1985;34:980-6.

114. Karjalainen J, Knip M, Hyöty H, Leinikki P, Ilonen J, Käär ML, et al. Relationship between serum insulin autoantibodies, islet cell antibodies and coxsackie-B4 and mumps virus-specific antibodies at the clinical manifestation of type 1 (insulin-dependent) diabetes. Diabetologia 1988;31:146-52.

115. Pak CY, Eun HM, McArthur RG, Yoon JW. Association of cytomegalovirus infection with autoimmune type 1 diabetes. Lancet 1988;2:1-4.

116. Hui JM, Sud A, Farrell GC, Bandara P, Byth K, Kench JG, et al. Insulin resistance is associated with chronic hepatitis $C$ virus infection and fibrosis progression [corrected]. Gastroenterology 2003;125:1695-704.

117. Mehta SH, Brancati FL, Sulkowski MS, Strathdee SA, Szklo M, Thomas DL. Prevalence of type 2 diabetes mellitus among persons with hepatitis $C$ virus infection in the United States. Ann Intern Med 2000;133:592-9.

118. Luna B, Feinglos MN. Drug-induced hyperglycemia.JAMA 2001;286:1945-8.

119. Zillich AJ, Garg J, Basu S, Bakris GL, Carter BL. Thiazide diuretics, potassium, and the development of diabetes: A quantitative review. Hypertension 2006;48:219-24.
120. Ribas A, Wolchok JD. Cancer immunotherapy using checkpoint blockade. Science 2018;359:1350-5.

121. Larkin J, Chiarion-Sileni V, Gonzalez R, Grob JJ, Cowey CL, Lao CD, et al. Combined nivolumab and ipilimumab or monotherapy in untreated melanoma. N Engl J Med 2015;373:23-34.

122. Borghaei H, Paz-Ares L, Horn L, Spigel DR, Steins M, Ready NE, et al. Nivolumab versus docetaxel in advanced nonsquamous non-small-cell lung cancer. N Engl J Med 2015;373:1627-39.

123. Reck M, Rodríguez-Abreu D, Robinson AG, Hui R, Csôszi T, Fülöp A, et al.; KEYNOTE-024 Investigators. Pembrolizumab versus chemotherapy for PD-L1-positive non-small-cell lung cancer. N Engl J Med 2016;375:182333.

124. Ferris RL, Blumenschein G Jr, Fayette J, Guigay J, Colevas AD, Licitra L, et al. Nivolumab for recurrent squamous-cell carcinoma of the head and neck. N Engl J Med 2016;375:1856-67.

125. Bellmunt J, de Wit R, Vaughn DJ, Fradet Y, Lee JL, Fong L, et al.; KEYNOTE-045 Investigators. Pembrolizumab as second-line therapy for advanced urothelial carcinoma. N Engl J Med 2017;376:1015-26.

126. Cheema A, Makadia B, Karwadia T, Bajwa R, Hossain M. Autoimmune diabetes associated with pembrolizumab: A review of published case reports. World J Oncol 2018;9:1-4.

127. World Health Organization. Report of a WHO Consultation. Definition, diagnosis and classification of diabetes mellitus and its complications.1. Diagnosis and Classification of Diabetes Mellitus. Geneva, Switzerland: WHO; 1999.

128. Rakocevic G, Floeter MK. Autoimmune stiff person syndrome and related myelopathies: Understanding of electrophysiological and immunological processes. Muscle Nerve 2012;45:623-34.

129. Lupsa BC, Chong AY, Cochran EK, Soos MA, Semple RK, Gorden P. Autoimmune forms of hypoglycemia. Medicine 2009;88:141-53.

130. Taylor SI, Barbetti F, Accili D, Roth J, Gorden P. Syndromes of autoimmunity and hypoglycemia. Autoantibodies directed against insulin and its receptor. Endocrinol Metab Clin North Am 1989;18:12343.

131. Uchigata Y, Eguchi Y, Takayama-Hasumi S, Omori Y. Insulin autoimmune syndrome (Hirata disease): Clinical features and epidemiology in Japan. Diabetes Res Clin Pract 1994;22:89-94.

132. Balasubramanyam A, Garza G, Rodriguez L, Hampe CS, Gaur L, Lernmark A, et al. Accuracy and predictive value of classification schemes for ketosis-prone diabetes. Diabetes Care 2006;29:2575-9.

133. Sobngwi E, Mauvais-Jarvis F, Vexiau P, Mbanya JC, Gautier JF. Diabetes in Africans. Part 2: Ketosis-prone atypical diabetes mellitus. Diabetes Metab 2002;28:5-12.

134. Khurshid Ahmad Khan JA. South Asian version of Flatbush diabetes mellitus-a case report and review article. Int J Med Med Sci 2009;1:347-52.

135. Tan KC, Mackay IR, Zimmet PZ, Hawkins BR, Lam KS. Metabolic and immunologic features of Chinese patients with atypical diabetes mellitus. Diabetes Care 2000;23:335-8.

136. Banerji MA, Chaiken RL, Huey H, Tuomi T, Norin AJ, Mackay IR, et al. GAD antibody negative NIDDM in adult black subjects with diabetic ketoacidosis and increased frequency of human leukocyte antigen DR3 and DR4. Flatbush diabetes. Diabetes 1994;43:741-5. 